\title{
DEA Analysis of Municipal Hospital Services and Scale After Hierarchical Medical Treatment Policy Was Implemented in China
}

Yuanyuan Li ( $\sim$ li-yoyo@163.com )

Gansu Provincial Hospital of Chinese Medicine https://orcid.org/0000-0002-5179-7983

\section{Yuzhu Wang}

Gansu Provincial Hospital of Chinese Medicine

\section{Yongqiang Zhao}

Gansu Provincial Hospital of Chinese Medicine

\section{Research article}

Keywords: DEA analysis, Return scale, Management policy, TCM hospitals

Posted Date: August 12th, 2020

DOI: https://doi.org/10.21203/rs.3.rs-42092/v1

License: (1) This work is licensed under a Creative Commons Attribution 4.0 International License.

Read Full License 


\section{Abstract}

Background: We aimed to provide decision basis for optimizing resource allocation by hospital administrators in China.

Methods: The samples were 18 municipal TCM hospitals of all public TCM hospitals of Gansu province in 2017. The BCC DEA model was employed to evaluate the relative efficiency of hospital operation. The slack variables in non DEA effective hospitals were employed to give the guidance how to achieve to the DEA effective.

Results: Firstly, the demands for medical services kept surging will lead to the scale return of most municipal-level TCM hospitals tend to the stable although part of it appear the decline or increase in return scale. Therefore, these municipal-level TCM hospitals should further pay attention to make full use of existing resources. Secondly, some municipal-level TCM hospitals with decline in return scale or increase in return scale should adopt different management measures for different situations, which in details in results and discussions sections.

Conclusion: After the implementation of healthcare policy such as graded diagnosis and treatment, hospital managers should learn advanced management concepts, use scientific management tools and software, carry out closed-loop management, make constant adjustments according to evaluation indicators, reduce management costs, and ensure the vitality of hospital operation.

\section{Introduction}

General office of the state council Accompanied by aging, urbanization and other social and economic transformation process in China, the current medical service system has still much irrationalities in medical treatment region and resource allocation at so on. In order to reach the comprehensive and balanced development of public service system, the government and healthcare providers must be forced to consider improving productivity, efficiency and quality of medical and health service institutions at all levels. A series of public health care reform policy was formulated and implemented by government to promote the long-term and healthy development of medical and health services and improve people's health for the past few years. Especially, with the hierarchical medical treatment policy was implemented in 2013 and the relative health resources were to skew towards the municipal hospital (1-3), the fee-forservice of inpatients and outpatients was further lowed. However, with the rapidly increase of the patients in the municipal hospital in the short term since the municipal hospital deserved more obligation than upper and lower levels, it was confronted with new pressure about how to further improving service quality and operational efficiency. Therefore, it has certain research value to evaluate the hospital efficiency after the specific policy was implemented and to provide decision basis for optimizing resource allocation by hospital administrators.

Data envelopment analysis (DEA), the non-parametric programming method introduced by Charnes, Cooper, and Rhodes(1978) (4), is a useful and appropriate tool and has been frequently used to 
objectively estimate hospital efficiency of decision making units(DMUs) in the past years. The main advantage of DEA is that it can relatively easily handle a multi-output and multi-input environment without specifying any functional form of the production relationship. Therefore, it can evaluate relative effectiveness of comparable DMUs according to multiple input and output indicators (5). As is known in the past relative literatures, DEA has two commonly used models including CCR model constant returns to scale (CRS) (4) and BCC model which account for variable returns to scale (VRS) (6), both of which used for the efficiency analysis of factor allocation under in the same static period. In the outputorientated BCC DEA model, it is supposition that there are independent and homogenous $\operatorname{DMUj}(j=1,2 \ldots$ $n)$. Every DMUj produces outputs by using $m$ inputs, and the inputs and outputs vectors are denoted as: $\mathrm{Xj}=(\mathrm{x} 1 \mathrm{j}, \ldots, \mathrm{xmj})$ and $\mathrm{Yj} \otimes(\mathrm{y} 1 \mathrm{j}, \ldots, \mathrm{ysj})(4)$. Based on the formula according to the literatures (7), the technical efficiency (TE), pure technical efficiency (PTE) and scale efficiency (SE) can be got, where numerical calculation relation is TE $=$ PTE $\times$ SE (4). According to the value of TE, PTE and SE, it can determine whether the DMUj technology and scale are effective. Not only that, TE can be also used to calculate the scale return, which refers to the change of output caused by the change of internal input in proportion with other conditions unchanged. The analysis of scale return including constant return to scale(CRS), increasing return to scale(IRS) and decreasing return to scale(DRS) is the relationship between the change of production scale and the change of production volume. After the above analysis of advantage, the BCC DEA model was employed to evaluate the relative efficiency of hospital operation in this paper.

This paper aims to evaluate the hospital efficiency in 18 municipal-level TCM hospitals in China in 2017, attempting to contribute to the existing literatures by providing the following management suggestions after the hierarchical medical treatment policy was implemented in 2013 (1). Firstly, the demands for medical services kept surging will lead to the scale return of most municipal-level TCM hospitals tend to the stable although part of it appear the decline or increase in return scale. Therefore, these municipallevel TCM hospitals should further pay attention to make full use of existing resources. Secondly, some municipal-level TCM hospitals with decline in return scale or increase in return scale should adopt different management measures for different situations, which in details in results and discussions sections. It is also concluded that from this paper, after the implementation of healthcare policy such as graded diagnosis and treatment, hospital managers should learn advanced management concepts, use scientific management tools and software, carry out closed-loop management, make constant adjustments according to evaluation indicators, reduce management costs, and ensure the vitality of hospital operation.

\section{Materials And Methods}

\section{Data source}

The data of this study come from the monitoring and direct reporting system of Traditional Chinese Medical service network. The samples were 18 municipal TCM hospitals of all public TCM hospitals of Gansu province in 2017, including 13 secondary hospitals and 5 tertiary hospitals. 
Methodology of DEA

Since the hospital production with constant returns to scale between inputs and outputs, the outputoriented BCC model was employed in this paper, because hospitals tend to serve more patients (8-10).

\section{Selection input and output indicators of the DEA model}

Firstly, 11 of all reported indicators were selected as input indicators and 7 as output indicators by

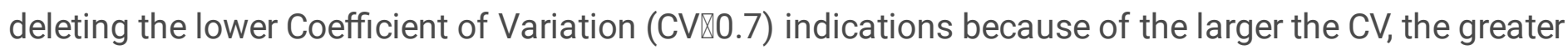
the sensitivity (11).

Secondly, taking the indicators with larger CV value, such as number of beds, number of employees, number of visits and discharges, as input-output indicators, the preliminary efficiency of the data of 18 hospitals in 2017 was calculated, and the preliminary value of TE was obtained. Then, taking TE as dependent variable and all input-output variables as independent variables, the stepwise multiple regression was carried out and the variables which have a significant effect on TE was obtained.

Finally, the number of staff囚the number of beds and square meters of the medical area $\left(\mathrm{m}^{2}\right)$ were used as input indicators, with the medical income (million Yuan), the number of outpatients (Outpat, thousand) and the number of inpatients (Inpat) were taken as the output indicators.

\section{Analytical tool}

The database was established with excel and SPSS19.0 was used for statistical analysis. Based on calculating the $\mathrm{CV}$ of all data, multiple regression analysis and correlation analysis were carried out, and the input and output indicators of the DEA were chosen as the DEA model. DEAP2.1 was used for data DEA analysis to evaluate the efficiency of 18 municipal TCM hospitals.

\section{Results}

\section{Correlation analysis}

Table 1 displays the basic statistics of variables and demonstrates the correlation coefficients of input and output variables. Strongly positive correlations between the inputs and outputs are apparent, satisfying the isotonicity property that an output does not decrease with increase in the input (8). The correlation coefficient between input and output indicators ranges from 0.537 to 0.855 .

\section{Result of DEA}

$\mathrm{H} 1-\mathrm{H} 18$ was used to represent 18 municipal hospitals of traditional Chinese medicine. Data from 18 hospitals were brought into DEAP2.1 for DEA-BCC analysis. The results were as follows (Table 2).

Among the 18 hospitals, DEA was effective in 7 hospitals, weak in 2 hospitals and non-DEA in 9 hospitals. With an effective rate of $38.89 \%$, the effective rate was relatively low. Most hospitals were in an 
invalid state, and the efficiency of each hospital was quite different, and two hospitals (TE $>0.9$ ) was in a marginal invalid state.

The scale returns of seven DEA effective hospitals are stable, which indicates that the development of these hospitals has entered a stable period. As long as the dynamic balance of input and output is maintained, the stable development of hospitals can be guaranteed. DEA of two hospitals is weak effective, but the scale returns of both hospitals are ineffective. This shows that the health service level and medical technology level of these two hospitals are compatible. The overall operation scale of these two hospitals is too large or too small, which leads to the weak effective DEA. The single input does not need to be adjusted, but the overall scale of the two hospitals should be reduced by expanding or reducing the scale efficiency from ineffective to effective, which all inputs should be expanded or reduced in equal proportion, so as to achieve DEA effectiveness. DEA is ineffective in nine hospitals, one of which has stable scale returns and PTE is ineffective, which indicates that the pure technical level of this hospital is relatively backward, and DEA can be achieved by improving the level of diagnosis and treatment technology and management. As is shown in table 3 , increasing returns to scale and ineffective economies of scale in four hospitals indicate that these four hospitals are small in scale and can expand their scale appropriately. Four hospitals have diminished returns to scale and ineffective economies of scale. The inputs of these four hospitals have not been fully converted into outputs, and appropriate scale control is needed to increase output.

\section{Slack variables in non DEA effective hospitals}

Non-DEA effective hospitals can be divided into two situations: 1) SE is effective, PTE is ineffective. Inadequate output resulted in redundancy of input and waste of resources. 2) Both SE and PTE are ineffective. Such hospitals are too large or too small to convert input into output effectively, resulting in redundancy of input and insufficiency of output. As shown in Table 4, all hospitals with ineffective DEA will achieve DEA validity by adjusting input and output appropriately according to relaxation variables.

\section{Compare the impact of DEA validity on inputs and outputs}

Eighteen hospitals are divided into two groups according to whether DEA is effective or not. Because the size of two hospitals with weak DEA is ineffective, they are classified into the ineffective group of DEA. The differences of input and output values between the two groups are compared, and the main causes leading to ineffective DEA are found out, which can provide reference values for effective policy formulation and decision-making direction adjustment in the future.

Normality test and homogeneity test of variance showed that medical income accorded with lognormal distribution $(P>0.05)$, other input-output indicators accorded with normal distribution $(P>0.05)$, and homogeneity of mean square deviation of all test indicators $(P>0.05)$. Independent simple test was selected to compare the differences between the two groups (as shown in Table 5). Except for the statistical difference in the number of outpatients $(P<0.05)$, there was no difference in the other groups. It can be concluded that the number of outpatients in DEA-effective hospitals is larger than that in DEA- 
ineffective hospitals. Hospitals with DEA-ineffective can achieve DEA-effective status by increasing the number of outpatients.

\section{Discussion}

\section{The overall low efficiency and great difference among municipal hospitals of traditional Chinese medicine}

Only 7 out of 18 hospitals have achieved DEA effectiveness, while the other 11 DEAs are weak or ineffective, the efficiency is only $38.89 \%$. Among them, $\mathrm{H} 3$ hospital has the lowest efficiency of 0.194 , and the range of efficiency is as high as 0.806 . The development of each hospital is extremely unbalanced. The unbalanced development results in the widening of regional differences in medical standards, which makes the difference different. The medical services enjoyed by the population in the region are uneven, and the current policy of graded diagnosis and treatment is set up to narrow the regional differences and improve the homogeneity of hospitals and the balance of medical care. Therefore, on the basis of implementing the existing graded diagnosis and treatment, it is necessary to increase the construction of municipal hospitals, narrow the gap between different hospitals in different regions, and make people enjoy equal medical services.

\section{Development Planning of Different Hospitals}

The implementation of graded diagnosis and treatment has brought tremendous changes to municipal public hospitals. Compared with the medical income of 18 hospitals in 2016, the number of outpatients and inpatients has increased by $12.95 \%, 20.35 \%$ and $7.05 \%$ on average. Faced with the sharp increase of patients, how to adjust the relationship between output and input is particularly important.

For the two hospitals with weak DEA efficiency, the input-output relaxation variable is 0 , the input-output of the hospital is basically reasonable, and the scale of operation is unreasonable. It is only necessary to expand or reduce the scale according to the existing scale.

For the Non-DEA effective hospitals, $\mathrm{H} 9$ was resulted in redundancy of input and waste of resources due to insufficient output. If we continue to blindly expand the input of tangible assets, which could not be converted into output, it will lead to scale inefficiency and scale compensation from stability to decline. Therefore, we should increase investment in intangible assets, such as improving medical care. technological level, the introduction of high-level personnel, the effective use of existing equipment and resources, improve management efficiency, etc., which will fully convert existing inputs into outputs so as to achieve DEA effectiveness. As for the other eight hospitals are ineffective in PTE and SE, the input and output of these hospitals are unreasonable and the scale of operation is unreasonable. we should adjust the input and output value according to the relaxation variable, and adjust the scale of operation to make it effective in DEA. 
The low output of hospitals was due to the technical problems in the utilization of health resources and the unreasonable supply structure. It is necessary not only to optimize the scale of hospital operation, but also to improve the utilization technology of resources. Vitaliano's research showed that there was a phenomenon of scale economy in hospitals, showing a U-shaped cost function curve. Hospital efficiency increased with the expansion of scale. After reaching the optimal scale, the efficiency of marginal input and output began to decline (12). With the deepening of the policy of graded diagnosis and treatment, the number of outpatients and inpatients in municipal hospitals will continue to increase in the next few years. Hospitals are facing the urgent need of transformation, development and efficiency improvement. In addition to supporting the corresponding hardware facilities, the construction of the hospital's own technical and management capabilities will be improved. Otherwise, blindly increasing investment will only result in a large amount of waste of investment capital. Now that many hospitals which expands too fast will result in uneconomical scale development and good appearance only, we should pay attention to the construction of connotation, so that technology development keeps pace with the development of scale.

\section{DEA difference analysis}

The analysis of DEA showed that only the number of outpatients had difference between DEA effective and non-DEA effective $(P<0.05)$. It could be concluded that the difference was caused by different outpatient outcomes. Because the reimbursement ratio of hospitalization expenses was higher than that of outpatient expenses in China's existing medical insurance policies, many patients who could have been treated in outpatient clinics tended to be hospitalized, which not only wasted limited medical resources, but also increased the workload of doctors, and to some extent caused ineffective output of hospitals. The purpose of graded diagnosis and treatment is to make effective use of existing health resources. Should patients be hospitalized? Which level of hospital should I stay in? It is a question to test the professional competence of doctors in municipal hospitals, as well as the management ability of municipal hospitals and the operational efficiency of the whole hospital. Introduce high-level talents, improve the professional ability of existing doctors, improve the management level of decision-making level, and improve the operation status of the hospital, so as to maximize the input and output of the whole hospital, and make effective use of all health services and health resources.

\section{Conclusion}

The nature of public hospitals determines that the medical market is not in a state of free competition. The expansion of scale and the introduction of large-scale advanced medical equipment have become the performance of hospital strength and competitive capital. If the increase of input is not accompanied by the improvement of soft power and management level, it will cause the problem of low utilization efficiency (13). At this time, only by improving the overall medical level and internal fine management level of the hospital to maximize the provision of high-quality medical services, the overall efficiency of the hospital was improved thereby. Each hospital is easy to pursue the scale of external construction, but

neglect the internal construction. Internal construction is also an intangible asset input. This intangible 
input develops slower than tangible asset input, but it also brings more output than tangible asset input. Hospitals should keep a dynamic balance between input and output, pay attention to the improvement of hospital efficiency, not blindly pursue the expansion of scale, and make full use of existing resources (14). DEA's effectiveness and inefficiency are mainly due to the insufficient output. Therefore, we should pay attention to the introduction and training of talents, encourage the innovation of diagnosis and treatment technology, improve work efficiency, improve the existing diagnosis and treatment process, diagnosis and treatment measures, and give full play to the role of advanced medical equipment (15). After the implementation of healthcare policy such as graded diagnosis and treatment, hospital managers should learn advanced management concepts, use scientific management tools and software, carry out closed-loop management, make constant adjustments according to evaluation indicators, reduce management costs, and ensure the vitality of hospital operation (16).

\section{Declarations}

\section{Ethics approval and consent to participate}

Not applicable.

\section{Consent for publication}

Not applicable.

\section{Availability of data and materials}

The datasets used and analysed during the current study are available from the author on reasonable request.

\section{Competing interests}

The authors declare that they have no competing interests.

\section{Funding}

Not applicable.

\section{Authors' contributions}

The author collected, analyzed and interpreted all the data, and was a major contributor in writing the manuscript. All authors read and approved the final manuscript.

\section{Acknowledgements}

The authors thank TCM monitoring and direct reporting network and all hospitals supplied the datum. 
The authors thank monitoring and direct reporting system of TCM service network and all hospitals supplied the datum.

The authors have no conflict of interest within the title page with a heading of conflict of interest.

\section{References}

1. CPC Central Committee and State Council (2013). Decisions of the CPC central committee on several major issues concerning comprehensively deepening reform. http://www.gov.cn/jrzg/201311/15/content_2528179.htm

2. General Office of the State Council (2014). The general office of the state council issued a notice on key tasks of deepening the reform of the medical and health system in 2014. http://www.gov.cn/zhengce/content/2014-05/28/content_8832.htm

3. General Office of the State Council (2015). Guiding opinions on promoting the construction of hierarchical medical treatment system. http://www.gov.cn/zhengce/content/201509/11/content_10158.htm

4. Charnes A, Cooper WW, Rhodes E (1978). Measuring the efficiency of decision making units. European Journal of Operational Research, 2: 429-444.

5. Hou W, Ren R (2001). Application of data envelopment analysis in efficiency evaluation of hospital. Chinese Journal of Health Statistics, 18(5):279-280.

6. Banker RD, Charnes A, Cooper WW (1984). Some models for estimation technical and scale efficiencies in data envelopment analysis. Management Science, 30: 1078-1092.

7. Banker RD, Thrall RM (1992). Estimation of returns to scale using data envelopment analysis. European Journal of Operational Research, 62: 74-84.

8. Hu HH, Qi QH, Yang CH, et al (2012). Analysis of hospital technical efficiency in China: Effect of health insurance reform. China Economic Review, (23): 865-877

9. Zhang N, Hu A, Zheng J (2007). Using data envelopment analysis approach to estimate the health production efficiencies in China. Frontiers of Economics in China, 2(1), 1-27.

10. Zhen W, Zhang C (2009), Efficiency Evaluation of China's New Rural Cooperative Medical System Using DEA Method, mimeo.

11. Zhang RH, LIU L, LI WH, et al (2011). Evaluating Efficiency of Health Services of 31 Provinces and Cities in China Based on DEA Model. Chinese Health Economics, 30(2): 69-71.

12. Vitaliano DF. On the estimation of hospital cost functions. Health Econ, 1987, 6(4): 305-318.

13. Xuan CY, Qi AJ (2017). DEA囚Based Evaluation of Efficiency of Level III General Hospitals in Shandong Province. Medicine and Society, 30(10): 51-53.

14. Pang ZM, Zhu JF, Yan ZL, et al (2017). Medical efficiency study of traditional Chinese medicine service in Guangdong province based on DEA model. Soft Science of Health, 31(11): 30-33 
15. Yuan J, Zhao LY, Man XW, et al (2015)囚DEA Analysis for Operating Efficiency of 72 Tertiary Traditional Chinese Medicine Hospitals in Western Region. Medicine and Society, 28(4): 47-49区 16. Chen JX, Li YJ (2016). Based on Data Envelopment Analysis (DEA) of Fujian Level 3 First-class Hospital Operation Efficiency Evaluation. Chinese Journal of Health Statistics, 33(5):749-751.

\section{Tables}

Table 1

Summary statistics of output and input variables (2015-2017)

\begin{tabular}{|c|c|c|c|c|c|}
\hline Variables & Mean & S.D. & \multicolumn{3}{|c|}{ Output-input correlation } \\
\hline \multicolumn{3}{|l|}{ Outputs } & Income & OUTPAT & INPAT \\
\hline Income(million Yuan) & 74.47 & 63.57 & \multicolumn{3}{|l|}{1.000} \\
\hline Outpat(thousand) & 177.67 & 139.96 & $0.827^{\star *}$ & \multicolumn{2}{|l|}{1.000} \\
\hline Inpat & 9748.61 & 6732.01 & $0.878^{\star *}$ & $0.827 * \star$ & 1.000 \\
\hline \multicolumn{6}{|l|}{ Inputs } \\
\hline Staff & 342.06 & 206.67 & $0.800 * \star$ & $0.736 * \star$ & $0.847^{\star \star}$ \\
\hline Beds & 365.17 & 226.22 & $0.818^{\star *}$ & $0.708 * \star$ & $0.855^{\star \star}$ \\
\hline $\operatorname{Area}\left(\mathrm{m}^{2}\right)$ & 20389.95 & 12203.77 & $0.756^{\star \star}$ & $0.537^{\star}$ & $0.561^{*}$ \\
\hline \multicolumn{6}{|c|}{ **: Correlation is significant at the 0.01 level (2-tailed). } \\
\hline \multicolumn{6}{|c|}{ *:Correlation is significant at the 0.05 level (2-tailed). } \\
\hline
\end{tabular}


Table 2

Result of DEA

\begin{tabular}{|llllll|}
\hline DMUs & TE & PTE & SE & Return to scale & Relative validity \\
\hline H1 & 0.914 & 0.946 & 0.966 & irs & Invalidity \\
\hline H2 & 1 & 1 & 1 & - & Validity \\
\hline H3 & 0.194 & 0.231 & 0.840 & irs & Invalidity \\
\hline H4 & 0.713 & 0.778 & 0.917 & irs & Invalidity \\
\hline H5 & 1 & 1 & 1 & - & Validity \\
\hline H6 & 1 & 1 & 1 & - & Validity \\
\hline H7 & 0.790 & 0.802 & 0.986 & drs & Invalidity \\
\hline H8 & 1 & 1 & 1 & - & Validity \\
\hline H9 & 0.697 & 0.697 & 1 & - & Invalidity \\
\hline H10 & 0.888 & 1 & 0.888 & drs & Weak validity \\
\hline H11 & 1 & 1 & 1 & - & Validity \\
\hline H12 & 0.830 & 0.868 & 0.956 & drs & Invalidity \\
\hline H13 & 1 & 1 & 1 & - & Validity \\
\hline H14 & 1 & 1 & 1 & - & Validity \\
\hline H15 & 0.749 & 0.753 & 0.995 & drs & Invalidity \\
\hline H16 & 0.979 & 1 & 0.979 & irs & Weak validity \\
\hline H17 & 0.720 & 0.899 & 0.801 & irs & Invalidity \\
\hline H18 & 0.702 & 0.719 & 0.976 & drs & Invalidity \\
\hline Means & 0.843 & 0.872 & 0.961 & & \\
\hline
\end{tabular}

Table 3

Analysis fo return to scale

\begin{tabular}{|lllll|}
\hline Value of efficiency & \multicolumn{3}{l}{ Return to scale } & Hospital \\
\cline { 2 - 4 } & crs & irs & drs & \\
\hline PTE $=1, \mathrm{SE}=1$ & 7 & 0 & 0 & $\mathrm{H} 2, \mathrm{H} 5, \mathrm{H} 6, \mathrm{H} 8, \mathrm{H} 11, \mathrm{H} 13, \mathrm{H} 14$ \\
\hline $\mathrm{PTE}=1, \mathrm{SE}<1$ & 0 & 1 & 1 & $\mathrm{H} 16 ; \mathrm{H} 10$ \\
\hline $\mathrm{PTE}<1, \mathrm{SE}=1$ & 1 & 0 & 0 & $\mathrm{H} 9$ \\
\hline $\mathrm{PTE}<1, \mathrm{SE}<1$ & 0 & 4 & 4 & $\mathrm{H} 1, \mathrm{H} 3, \mathrm{H} 4, \mathrm{H} 17 ; \mathrm{H} 7, \mathrm{H} 12, \mathrm{H} 15, \mathrm{H} 18$ \\
\hline
\end{tabular}


Table 4

Slack variable of DEA invalid hospitals

\begin{tabular}{|c|c|c|c|c|c|c|}
\hline \multicolumn{2}{|c|}{ Hospital $\mathbf{S}^{1-}$} & $s^{2-}$ & $s^{3-}$ & $S^{1+}$ & $s^{2+}$ & $s^{3+}$ \\
\hline $\mathrm{H} 1$ & 225.825 & $5238.81 \mathrm{c}$ & 90.000 & 9.233 & 26.739 & 627.795 \\
\hline$J$ & 21.462 & 0.000 & 9768.846 & & & 69 \\
\hline 14 & 0.0 & & & & & \\
\hline 17 & & & & & & \\
\hline 9 & & & & & & \\
\hline 172 & & 0.0 & & & & \\
\hline & & & & & & \\
\hline 117 & 50. & 0.000 & 0.000 & 2.675 & & 388.172 \\
\hline 18 & & 30.000 & & 38.461 & & \\
\hline
\end{tabular}

Table 5

Compare the impact of DEA validity on inputs and outputs(_x \pm s)

\begin{tabular}{|c|c|c|c|}
\hline Variables & Validity & Invalidity & $P$ \\
\hline Num of DMUs & 7 & 11 & \\
\hline Outputs & & & \\
\hline $\begin{array}{l}\text { Income(million Yuan) } \\
\text { Outpat(thousand) }\end{array}$ & $\begin{array}{l}76.61(55.83,105.14) \\
258.74 \pm 161.17\end{array}$ & $\begin{array}{l}37.23(18.51,74.89) \\
126.08 \pm 100.94\end{array}$ & \begin{tabular}{|l|}
0.116 \\
$0.046 *$
\end{tabular} \\
\hline Inpat & $12477.86 \pm 7524.27$ & $8011.82 \pm 5877.32$ & 0.177 \\
\hline Inputs & & & \\
\hline Staff & $364.29 \pm 209.59$ & $327.91 \pm 213.74$ & 0.728 \\
\hline Beds & $375.71 \pm 205.58$ & $358.45 \pm 248.01$ & 0.880 \\
\hline Area $\left(\mathrm{m}^{2}\right)$ & $18606.72 \pm 9000.8$ & $21524.74 \pm 14175$ & 0.635 \\
\hline
\end{tabular}

